\title{
Rural and Urban Counties in Idaho: Differences in Vocational Rehabilitation Service Delivery and Outcomes
}

\author{
Andrew Grey ${ }^{1}$ a \\ ${ }^{1}$ Idaho Division of Vocational Rehabilitation \\ Keywords: outcomes, vocational rehabilitation, rural, urban \\ https://doi.org/10.52017/001c.27234
}

\section{Rehabilitation Counselors and Educators Journal}

Vol. 10, Issue 2, 2021

\begin{abstract}
The Idaho Division of Vocational Rehabilitation (IDVR) sought to learn whether differences in VR service delivery and employment outcomes were present among consumers residing in urban and rural areas of the state. Case data for participants who had an Individualized Plan for Employment (IPE) signed and in place with the agency between $7 / 1 / 2017$ and 6/30/2020 were examined to identify differences in employment outcomes and service delivery by county. A total of 7,235 cases were examined, 5,963 (82\%) of which were residents of urban areas and 1,272 (18\%) were from rural counties. Specific evaluation questions examined differences between these two groups regarding types of services provided to VR participants and length of time between initial IPE signature and service received. Analysis of administrative data indicated that training services were provided at a higher rate to participants in rural counties, whereas job search assistance, assessment, transportation, and maintenance services were provided at a higher rate to participants in urban counties. The overall successful case closure rate for urban (41.42\%) and rural participants (41.80\%) was comparable.
\end{abstract}

\section{Background and Purpose}

Idaho has a distinct divide between urbanized and nonurbanized geographic areas with 12 (27\%) of the 44 counties in Idaho identified as "metro", and the remaining 32 (73\%) counties as rural (United States Census Bureau, 2013). The literature has shown that individuals living in rural areas face a number of significant challenges to accessing services from a wide range of programs. The Office of Management and Budget defines metropolitan counties as those with one or more densely settled urban entity with 50,000 or more people (Office of Management and Budget, 2020). According to the United States Department of Agriculture (2017), the employment rate in non-metro counties in the United States has historically been significantly lower than the employment rate for metro counties. While the number of available jobs in both metro and non-metro counties declined after the first quarter of 2008 to the end of 2009 as a result of the Great Recession, employment in metro counties subsequently surpassed its 2008 peak by 2015, while non-metro employment is still below the levels it was at prior to the great recession (United States Department of Agriculture, 2017).

The Idaho Department of Labor defines Idaho as a rural state, with $28 \%$ of the state's population living in rural counties, compared with an average of $20 \%$ nationwide. While Idaho's economic activity as a whole has shifted to- ward a service-oriented economy with a greater share of employment opportunities in these areas, rural counties have tended to remain focused on agricultural or mining industries. The result is that urban counties in Idaho present more diverse employment opportunities. In addition, employment growth rates across all industries have consistently been higher in Idaho's urban counties than in its rural counties (Idaho Department of Labor, 2018).

Rural residents in general, including those with disabilities, frequently experience barriers to employment caused by their living in a rural setting. A focus group of Great Plains residents noted barriers unique to rural areas, including the relatively low number of available jobs, higher rate of seasonal work, lower pay, and need to travel longer distances for work and other services (Cochran et al., 2002). Studies of VR counselors and consumers have demonstrated similar issues, with the most pressing barriers for rural consumers being (a) a lack of public and private transportation, (b) insufficient local employment and training opportunities, and (c) a lack of services for people with disabilities (Arnold \& Seekins, 1998; Rojewski, 1992). Lustig, Strauser, and Weems (2004) further noted that rural residents have less access to mental health resources, while also experiencing a higher rate of mental health concerns. Rigles and colleagues (2011) interviewed rural VR consumers who had exited the program "prematurely" and noted frustration with the lack of employment opportunities in their 
communities, a lack of “anonymity” when navigating job terminations and criminal history, and the slow pace of VR services. Providing VR services to individuals in rural counties can also pose unique challenges for VR agencies and their staff.

The purpose of this study was to identify whether any detectable differences existed between rural and urban consumers, propose reasons any differences may be occurring, and suggest steps that might be taken to expand understanding of differences between service delivery in rural versus urban counties or resolve and identify problems. The research questions were (a) are there differences between the types of services provided to individuals in rural and urban counties?; and (b) are there differences in the successful closure rate for participants in urban and rural counties?

\section{Methods}

This study examined case data from the Idaho Division of Vocational Rehabilitation (IDVR) for VR cases with an initial Individualized Plan for Employment (IPE) date between $7 / 1 / 2017$ and 6/30/2020 to learn whether significant differences exist between the manner and efficiency in which services are provided to VR participants in rural and urban counties. Case records of 7,235 consumers with an initial IPE during the specified dates were identified in the IDVR case management system. Data on services purchased for these individuals was reviewed and the percentage of rural and urban participants who received each type of service, sorted by Rehabilitation Services Administration (RSA) service category, was calculated. Additionally, the percentage of rural or urban cases closed successfully was identified and chi-square testing was used to determine significance.

The case data for all IDVR participants is stored in a set of connected data tables. Queries were developed to pull data on services authorized to IDVR participants based on the initial IPE date. Authorization information was tied to the case and participant to whom the service was provided. Case information included the date of the participant's initial IPE, the closure outcome of the case if the case was closed, and the county of residence at the time the individual applied for VR services. Successful closure was defined as cases closed after at least 90 days of verified stable employment matching a participant's employment goal on their IPE.

\section{Results}

Findings from this study suggested significant differences in the types of services provided to VR participants in Idaho, depending on whether they were served in rural or urban counties. Specifically, VR participants in rural counties were more likely to receive training services, whereas participants in urban counties were more likely to receive job search and placement assistance. Interestingly, these differences in service delivery did not appear to lead to a significant change in ultimate case success or failure.

\section{Service Delivery}

RSA divides services purchased by VR agencies into 36 unique categories. Eight of the categories (Randolph-Shep- pard, customized training, counseling and guidance, job placement assistance, information and referral, benefits counseling, personal assistance services, and reader services) were not purchased after the consumer's initial IPE and were therefore excluded from this evaluation. A chisquare test on the rates at which services were provided to participants who received any of the remaining 28 types of services showed a significant difference $(\mathrm{p}<0.05)$ in 14 service categories: (a) assessment, (b) counseling on enrollment activities, (c) diagnosis and treatment of impairments, (d) instruction in self-advocacy, (e) job readiness training, (f) job search assistance, (g) maintenance, (h) other services, (i) supported employment services, (j) transportation, and (k) work based learning; all were purchased at a significantly higher rate for residents of urban counties. Conversely, four other services (a) four-year college training, (b) occupational or vocational training, (c) on-the-job training, and (d) other services were purchased at a significantly higher rate in cases with residents of rural counties. See Table 1.

\section{Successful Case Closure}

In terms of successful case closure rates, there was no statistically significant difference between consumers in urban and rural counties. Of the 3,665 urban cases closed after IPE, 1,518 (41.42\%) were closed successfully, while 316 (41.80\%) of the 756 rural cases were closed successfully.

\section{Recommendations and Implications for Practice}

The lack of statistically significant differences between the case outcomes for consumers served in rural counties versus those served in urban counties would seem to indicate there are no apparent concerns or considerations in the service delivery model. However, the results of the project pose other questions that could be investigated further why are different service types favored in rural communities and others in urban communities? Additional research could shed additional light on this issue. For example, are there significant differences among participants being served in rural areas, as opposed to urban areas? What are the motivations of VR staff for developing different service delivery strategies in different communities? Are the differences in service delivery models a function of the job opportunities in these communities or a function of the available vendors for these services?

Based on findings from this study, points of interest that may be applicable to other VR agencies include:

- The significantly higher rate at which participants in rural Idaho received training services may indicate that the economies of rural areas do not present appropriate employment opportunities to meet the skill level of these individuals.

- The lower rate at which rural VR participants received job search and job retention services may be related to the types of jobs available in the community, as well as the availability of vendors providing these services.

- Differences in service delivery models in rural, as opposed to urban communities, do not necessarily 
Table 1. Vocational Rehabilitation Services Received in Urban and Rural Counties

\begin{tabular}{|c|c|c|c|c|}
\hline \multirow[t]{2}{*}{ RSA category } & \multicolumn{2}{|c|}{ Urban } & \multicolumn{2}{|c|}{ Rural } \\
\hline & $\mathrm{n}$ & $\%$ & $\mathrm{n}$ & $\%$ \\
\hline Assessment* & 1749 & 29.33 & 316 & 24.84 \\
\hline Counseling on enrollment activities* & 66 & 1.11 & 5 & 0.39 \\
\hline Diagnosis and treatment of impairments* & 660 & 11.07 & 115 & 9.04 \\
\hline Four-year college training* & 181 & 3.04 & 63 & 4.95 \\
\hline Instruction in self-advocacy* & 116 & 1.95 & 8 & 0.63 \\
\hline Job readiness training* & 98 & 1.64 & 1 & 0.08 \\
\hline Job search assistance* & 1817 & 30.47 & 313 & 24.61 \\
\hline Maintenance* & 1014 & 17.00 & 115 & 9.04 \\
\hline Occupational or vocational training* & 540 & 9.06 & 167 & 13.13 \\
\hline On-the-job training* & 31 & 0.52 & 20 & 1.57 \\
\hline Other services* & 890 & 14.93 & 221 & 17.37 \\
\hline Supported employment services* & 455 & 7.63 & 74 & 5.82 \\
\hline Transportation* & 1244 & 20.86 & 208 & 16.35 \\
\hline Work-based learning* & 337 & 5.65 & 54 & 4.25 \\
\hline Customized employment services & 2 & 0.03 & 1 & 0.08 \\
\hline Disability-related skills training & 1 & 0.02 & 0 & 0.00 \\
\hline Extended services & 2 & 0.03 & 0 & 0.00 \\
\hline Graduate training & 16 & 0.27 & 2 & 0.16 \\
\hline Interpreter services & 58 & 0.97 & 10 & 0.79 \\
\hline Job exploration counseling & 0 & 0.00 & 6 & 0.47 \\
\hline Junior or community college training & 104 & 1.74 & 31 & 2.44 \\
\hline Miscellaneous training & 363 & 6.09 & 66 & 5.19 \\
\hline Registered apprenticeship training & 7 & 0.12 & 0 & 0.00 \\
\hline Rehabilitation technology & 764 & 12.81 & 171 & 13.44 \\
\hline Remedial training & 9 & 0.15 & 0 & 0.00 \\
\hline Short-term job supports & 803 & 13.47 & 123 & 9.67 \\
\hline Technical assistance services & 9 & 0.15 & 0 & 0.00 \\
\hline Workplace readiness training & 347 & 5.82 & 58 & 4.56 \\
\hline
\end{tabular}

equate to differences in the rate of successful case closure.

\section{Author Note}

The contents of this paper were developed under a co- operative agreement with the U.S. Department of Education, Technical Assistance Center for Vocational Rehabilitation Agency Program Evaluation and Quality Assurance (PEQA-TAC) (Grant Award Number: H263B150004). However, the contents and views expressed in this publication do not necessarily represent the positions or policies of the U.S. Department of Education, and you should not assume endorsement by the Federal government. 


\section{References}

Arnold, N. L., \& Seekins, T. (1998). Rural and urban vocational rehabilitation: Counselors perceived strengths and problems. Journal of Rehabilitation, 64(1), 5-13.

Cochran, C., Skillman, G. D., Rathge, R. W., Moore, K., \& Johnston, J. (2002). A rural road: Exploring economic opportunity, networks, services and supports that affect rural families. Child Welfare, 81(5), 837-848.

Idaho Department of Labor. (2018, July). Idaho economy: The future of rural Idaho. https://www.labor.idaho.go v/dnn/Portals/0/Publications/Future of Rural_Idah o_FINAL.pdf

Lustig, D. C., Strauser, D. R., \& Weems, G. H. (2004). Rehabilitation service patterns: Rural/urban comparison of success factors. Journal of Rehabilitation, 70(3), 13-19.

Office of Management and Budget. (2020, April 1). Metropolitan and micropolitan. https://www.census.go v/programs-surveys/metro-micro/about.html
Rigles, B., Ipsen, C., Arnold, N., \& Seekins, T. (2011). Experiences of rural vocational rehabilitation clients who leave the system prematurely: A qualitative exploration. Rehabilitation Counseling Bulletin, 54(3), 164-174. https://doi.org/10.1177/0034355210396948

Rojewski, J. W. (1992). Vocational rehabilitation in rural America: Challenges and opportunities. American Rehabilitation, 18(1), 39-44.

United States Census Bureau. (2013, February). IdahoCore based statistical areas (CBSAs) and counties. http s://www2.census.gov/geo/maps/metroarea/stcbsa_pg/ Feb2013/cbsa2013_ID.pdf

United States Department of Agriculture. (2017, July 6). Rural employment and unemployment. https://www.er s.usda.gov/topics/rural-economy-population/employ ment-education/rural-employment-and-unemployme nt/ 